\title{
Desigualdades y cambios en los hábitos alimenticios: del influjo prioritario de la familia al de la socialización mediática
}

\author{
Francisco EnTRENA-DURÁn \\ Universidad de Granada (España) \\ fentrena@ugr.es \\ José Francisco JiMÉNEZ-DÍAZ \\ Universidad Pablo de Olavide, de Sevilla (España) \\ josefco@upo.es
}

\begin{abstract}
Resumen
Los hábitos alimenticios han pasado de desarrollarse prioritariamente dentro de la familia a estar cada vez más influidos por los medios de comunicación y la publicidad. En este contexto, en el que se observan tendencias hacia la individuación y consiguiente pérdida de sociabilidad del acto de comer, las disparidades en los niveles de recursos económicos, educativos y/o informativos sitúan a las personas en desiguales condiciones para acceder a los bienes alimenticios, al tiempo que constituyen factores clave para la producción y reproducción de su identidad y/o grado de distinción social.
\end{abstract}

Palabras Clave: Hábitos alimenticios; familia; medios de comunicación; publicidad; desigualdad y distinción social.

\section{Inequalities and changes in eating habits: from the priority of family influence} to the key impact of media socialization

\begin{abstract}
Eating habits have shifted from being mostly developed within the family to become increasingly influenced by media and advertising. In these circumstances, in which we are witnessing trends toward the individuation of the eating act with its subsequent sociability loss, their socioeconomic, educational and/or informational disparities place people in unequal conditions for accessing to food commodities. In turn, these disparities are key factors for the production and reproduction of both people identity and their degree of social distinction.
\end{abstract}

Keywords: Eating habits; family; communication media; advertising; inequality and social distinction.

\section{Referencia normalizada:}

Entrena Durán, F.; Jiménez Díaz, J. F. (2013) Desigualdades y cambios en los hábitos alimenticios: del influjo prioritario de la familia al de la socialización mediática. Historia y Comunicación Social. Vol. 18 $\mathrm{N}^{\mathrm{o}}$ Especial Noviembre. Págs. 151-161.

Sumario: 1. Introducción. 2. Metodología. 3. Entre la búsqueda de la distinción y el seguimiento de los patrones normalizados de alimentación. 4 . Sobre el cuerpo ideal, la tiranía del éxito y la pérdida de la sociabilidad de la comida. 5. A modo de conclusión. 6. Referencias bibliográficas. 


\section{Introducción}

Durante milenios la familia ha sido la principal institución económica y socializadora de los seres humanos. Sin embargo, con el desarrollo y evolución de las sociedades modernas comienza un proceso de progresiva diferenciación social que hace que una serie de papeles desempeñados tradicionalmente por la institución familiar pasen a ser realizados por otras instituciones. Por ejemplo, la socialización y la educación de las personas son compartidas por la familia con las instituciones educativas. Particularmente, en lo relativo a la educación primaria, es deseable que fomente el conocimiento y el aprecio del propio cuerpo, a la vez que contribuya a su desarrollo inculcando hábitos adecuados para la salud, el bienestar y la calidad de vida. Respecto a la secundaria, debe seguir esta misma línea, concienciando sobre los beneficios que suponen el ejercicio físico, la higiene, la alimentación equilibrada y la vida sana (López, 1999: 7).

La educación reglada y los medios de comunicación de masas tienen un creciente papel socializador en las sociedades avanzadas actuales (Marín, 2006). Esto hace que los procesos de producción y reproducción de los hábitos alimenticios estén cada vez más condicionados por instancias ajenas a la institución familiar, como por ejemplo la agroindustria transnacional, cuyas estrategias productivo-publicitarias y de venta tienen un decisivo papel en la formación social de las preferencias alimenticias de las personas (Harris, 1985). Hablamos de formación social de tales preferencias, ya que, tanto el hecho de que determinados alimentos sean considerados como apetecibles y deseables, como el que existan aversiones hacia otros, han de ser entendidos como el resultado de actitudes alimenticias socialmente construidas. Actitudes que, por consiguiente, son algo adquirido que, más que en las supuestas cualidades nutricionales de los alimentos, se sustenta, muy especialmente, en las significaciones culturales que los sujetos han aprendido a atribuirles a éstos y/o a su consumo a través de procesos de socialización alimenticia específicos y en función del contexto socio-cultural y/o territorial en el que se han desarrollado como personas sociales.

Por tanto, lo que una sociedad considera como 'comida normal', o incluso como 'muy rico', otra lo puede percibir como 'repugnante' o 'inaceptable', pues el acto de comer es un hecho social configurado por las preferencias alimenticias adquiridas culturalmente en la vida cotidiana de los sujetos y colectivos durante sus procesos socializadores (Restrepo y Maya-Gallego, 2005: 141-144). Así, muchos africanos, asiáticos, europeos o americanos suelen apreciar y consumir la leche animal, pero los chinos raramente la consumen. Las langostas, los cangrejos y los camarones son vistos como alimentos valiosos y delicados por numerosos europeos y norteamericanos, pero son considerados como repulsivos por otros muchos africanos y asiáticos; sobre todo, los/as que residen lejos del mar. Los franceses consumen carne de caballo pero los ingleses generalmente no. Para muchas personas resulta exquisita la carne de monos, serpientes, perros y ratas o determinados insectos, pero muchas otras juzgan muy desagradables estos alimentos. Las creencias religiosas prohíben el consumo de algunos alimentos e incluso obligan a ayunar durante ciertos periodos 
del año, tal y como sucede entre los musulmanes en el mes del Ramadán o entre los católicos algunos días de la Semana Santa. Igualmente, los musulmanes y los judíos no pueden comer carne de cerdo, y los hindúes no comen carne y con frecuencia son vegetarianos. Así, dentro de la variedad de alimentos existentes, cada grupo elige uno en especial. Los factores que influyen en tal elección pueden ser: el lugar de residencia, las decisiones políticas, la situación económica, el clima, el transporte, las influencias mediáticas, la educación o los gustos personales (Guerrero, Campos y Luengo, 2005).

Por otra parte, la socialización alimenticia de las personas no puede entenderse al margen del hecho de que éstas, en tanto sujetos que ocupan posiciones desiguales y tienen trayectorias vitales e identidades individuales y colectivas variadas, son propensas a mantener perspectivas o actitudes diversas, plurales y más o menos críticas hacia los hábitos y las predisposiciones alimentarias adquiridas. Una propensión a la crítica que, como veremos aquí, no se reparte uniformemente, sino en grados desiguales y diferentes según cada estrato social; como desiguales y diferentes son las peculiaridades de los sujetos sociales, las situaciones biográficas y los mundos cotidianos concretos que éstos experimentan y definen (Schütz, 1974), así como sus respectivas socializaciones.

\section{Metodología}

La metodología seguida para la realización de este trabajo ha consistido en llevar a cabo una experiencia docente de recopilación, discusión y análisis, conjuntamente entre el profesor y el alumnado universitario de Sociología, de referencias bibliográficas, anuncios publicitarios en prensa u otros medios, así como de publicaciones especializadas, informes o artículos acerca del consumo alimenticio. La finalidad básica de ello ha sido proporcionar a dicho alumnado contenidos, marcos teóricos y habilidades profesionales en lo relativo a mejorar su capacidad para comprender y/o investigar el influjo de los medios de comunicación en la producción y reproducción de los hábitos alimenticios de la ciudadanía. Sin embargo, también se ha conseguido acrecentar el grado de concienciación y educación cívica de los participantes en tal experiencia en lo que respecta a sus propias prácticas y estrategias alimentarias.

Un objetivo primordial ha sido, además de concienciar a los participantes en la necesidad de adoptar prácticas alimentarias sostenibles y sanas, capacitarlos, en tanto que científicos sociales en formación, para entender y analizar la dimensión social de la alimentación humana. En este sentido, se ha procurado siempre resaltarles el hecho de que, si bien comemos por necesidad biológica, los hábitos alimenticios humanos se producen y reproducen socialmente mediante los procesos de socialización. Procesos en los que los medios de comunicación adquieren un creciente papel, ofreciendo nuevas alternativas, al tiempo que se relega paulatinamente la función clave desempeñada a este respecto por la familia. 
Otro propósito central ha sido fortalecer la capacidad de crítica del alumnado ante la realidad del consumo alimenticio. Se trata de fomentar en él un aprendizaje reflexivo/reactivo que no se limite a la mera recepción de contenidos y conceptos, sino que también le incite a implicarse en el necesario cambio de los valores y de las reglas de juego y, consecuentemente, en la lucha dirigida a superar las problemáticas sociales, económicas, políticas o sanitarias inherentes a dicho consumo.

En consonancia con la metodología seguida, las consideraciones sobre dicho consumo que se hacen aquí son producto, no sólo de las habilidades teórico-interpretativas de quienes esto escriben, sino que también es justo reconocer lo que tales habilidades hayan podido mejorar con la lectura y/o la consideración de las reflexiones del alumnado sobre los documentos e informes trabajados en la acción docente.

\section{Entre la búsqueda de la distinción y el seguimiento de los patrones normali- zados de alimentación}

Los estratos sociales bajos suelen ser menos críticos en sus opciones de consumo alimenticio. Por ello resultan más fácilmente influenciables por los mensajes publicitarios. En cambio, los estratos sociales superiores suelen ser más críticos a este respecto, tal y como se corresponde con su mayor poder adquisitivo y superior preparación intelectual, lo que les proporciona más facilidades para acceder a medios especializados, tales como semanarios de prensa o determinadas revistas científicas con mensajes y discursos más elaborados acerca de la alimentación y de lo que se considera una vida saludable. Ello ha sido confirmado en diversos estudios empíricos como, por ejemplo, en una investigación de los jóvenes chilenos y su distinta percepción de la publicidad, la cual es vista por los estratos altos de dichos jóvenes como una experiencia de tipo estético, cuya valoración viene dada fundamentalmente por su creatividad, su capacidad de persuasión y los 'insight' utilizados. Por contra, en los estratos bajos, su valoración de la publicidad manifiesta ser menos crítica; es decir, su atención se concentra en la dimensión informativa del fenómeno publicitario con respecto al precio y a las ofertas presentadas (Vergara-Leyton y Rodríguez-Salineros, 2010: 118).

En las actuales sociedades desarrolladas hace ya tiempo que quedaron atrás las hambrunas cíclicas que producían muertes masivas por inanición. Las mayores o menores dificultades para conseguir la comida necesaria han dejado de ser un factor de diferenciación entre 'pobres' y 'ricos'. Esa diferenciación se manifiesta hoy, sobre todo, como disparidad en los niveles de recursos económicos, educativos o informativos, lo que sitúa a las personas en desiguales condiciones para acceder a bienes alimenticios de mejor o peor calidad. Así, al mismo tiempo que entre los estratos bajos suele extenderse la obesidad porque se ven más abocados a consumir la más barata y grasienta 'comida basura', en los sectores medios y altos, con niveles socioeconómicos, culturales y adquisitivos más elevados ( $\mathrm{y}$, por lo tanto, con mayor capacidad de elección), se observan tendencias hacia una gradual preocupación por la 
calidad. Preocupación que refleja cómo los hábitos determinantes de la adquisición y el consumo de alimentos están cada vez más influidos por lo que se podría conceptuar como valores y actitudes de índole postmaterialista (Inglehart, 1990).

Para estos sectores sociales con niveles de ingresos más altos, los hábitos alimenticios actúan como actos de diferenciación y de construcción de su identidad individual o colectiva en la vida cotidiana, contribuyendo, por consiguiente, a propiciar en ellos un mayor o menor grado de distinción social, de clase o de status (Bourdieu, 1988; Restrepo y Maya-Gallego, 2005: 142). Por otra parte, aunque en los estratos sociales con menores ingresos también se observan indicios de esa búsqueda de la distinción, lo que prevalece en la generalidad de tales estratos es ese patrón estándar masificado de consumo alimenticio dominante entre la gran mayoría de la población mundial. Dicho patrón es seguido de manera particularmente intensa por los colectivos más vulnerables o influenciables como, por ejemplo, los niños y los jóvenes (Hidalgo, 2003), así como por todos aquellos con niveles socioeconómicos y/o educativos más bajos, tales como los parados de larga duración o los inmigrantes de menos recursos (Alonso, 2002).

\section{Sobre el cuerpo ideal, la tiranía del éxito y la pérdida de la sociabilidad de la comida}

Actualmente se extienden las preocupaciones por la salud y por lo ecológico, a la vez que la publicidad y los medios de comunicación de masas suelen difundir globalmente imágenes muy similares acerca del cuerpo ideal y del estilo de vida deseables. Los efectos de esta 'homogeneización' de los repertorios alimenticios (Contreras-Hernández y Gracia-Arnaiz, 2005: 426-435) no se muestran uniformemente entre todos los colectivos sociales, sino de modo distinto según la clase social o grupo de ingresos, cada uno de los cuales desarrolla diferentes hábitos de alimentación y considera deseables unas imágenes específicas del cuerpo, en consonancia con su particular forma y expectativas de vida (Bourdieu, 1971). Por ejemplo, se ha comprobado que en Inglaterra existen notables diferencias en las pautas de gasto alimenticio y en los tipos de productos consumidos, según se sea obrero o de clase media (Warde, 1997). Ello tiene mucho que ver con las disimilitudes sociales en la generación del gusto alimenticio, por lo general conformado en torno a sabores aprendidos socialmente desde la infancia (González-Turmo, 1995: 309).

Las personas que por su status socio-cultural tienen suficiente margen de elección no comen cualquier cosa, sino lo que consideran les acerca al estilo de vida deseado o a la imagen corporal con la que se identifican y que pretenden sea su 'fachada' (front), a fin de definir la situación respecto a los observadores de las actuaciones cotidianas de dichas personas (Goffman, 1959). Esa imagen corporal es distinta por grupos de edad y también difiere según el género. Así, si bien son las chicas las que presentan más frecuentemente un índice normalizado de masa corporal y los chicos los que 
padecen más sobrepeso y obesidad, la percepción del propio cuerpo como obeso es mayor entre las chicas (Ramos, Rivera y Moreno, 2010).

La percepción del cuerpo ideal está muy relacionada con los discursos contemporáneos sobre el mismo y la salud desarrollados por los medios de comunicación y/o información dominantes. Discursos que contribuyen a promover diversas prácticas de cuidados corporales y formas de alimentación en el mundo actual (Martínez, 2004: 148). Prácticas y cuidados que son muy diferentes para cada grupo social o de ingresos (Shilling, 1993), de tal forma que las clases alta y media no anhelan un cuerpo robusto, sino sano, el cual entienden como delgado. Conseguir ese tipo de cuerpo y mantenerlo supone un auténtico esfuerzo de austeridad en el comer y la práctica regular de ejercicio físico, lo que, a su vez, implica un constante sacrificio y autocontrol. Esto puede llegar a ser extremo en el caso de que suponga la supeditación de los sujetos a una especie de tiranía del éxito mediante su amoldamiento a la particular estética de unas imágenes corporales, frecuentemente, tan estereotipadas y al margen de la realidad natural del cuerpo como difíciles de lograr (Corti, 2005).

Desde luego, la referida supeditación a la tiranía del éxito es más característica de las mejor formadas educacionalmente clases medias y altas, y no tanto de las bajas, cuya imagen corporal deseable suele estar más ligada al mayor esfuerzo físico de los trabajos que aspiran a realizar y/o con sus menores niveles adquisitivos. Por ejemplo, entre las amas de casa de las clases populares en Andalucía (España), de más edad e inferior nivel educativo, se activan un conjunto de esquemas a la hora de valorar su cuerpo, la alimentación y la salud familiar, tales como 'no mirarse demasiado', 'saber disfrutar' y 'tener buena boca'; mientras que entre las madres más jóvenes y con mayor capital cultural la buena madre es sobre todo la que procura estar informada y concienciada, la que posee mayor grado de conocimiento para disciplinar la alimentación de sus hijos (Martín-Criado y Moreno-Pestaña, 2005: 44).

Por otra parte, los dispares horarios laborales impiden que los diferentes miembros de la familia, salvo en las festividades o periodos vacacionales, puedan comer habitualmente juntos y, en cambio, tengan que hacerlo en soledad. Esto rompe con lo que ha sido nuestra ancestral tradición como especie humana que se desarrolló socialmente consiguiendo y compartiendo la comida en grupo. En suma, el hecho de comer no sólo tiene como función primordial la de proporcionarnos la nutrición necesaria, sino que también es un acto con sentido socio-cultural, al tiempo que generador y/o fortalecedor de los vínculos de sociabilidad. Por ello, la anomia del, usualmente solitario, comensal del globalizado mundo moderno constituye un síntoma característico de nuestro tiempo, una de las causas del malestar psicosocial actual. Así, a la crisis mundial derivada de las grandes desigualdades u obstáculos para acceder a los alimentos, que propicia que gran parte de la humanidad sufra el hambre y la desnutrición, hay que añadir esa otra crisis humana de la anomia derivada de la pérdida de la sociabilidad del hecho de comer, calificada como 'gastro-anomia' o 'alimentación desestructurada’ (Contreras-Hernández y Gracia-Arnaiz, 2005: 441-451). 
Dicha 'gastro-anomia' puede estar llevando a una falta o debilitamiento de las normas, así como a una carencia de criterios socio-culturales para elegir lo que comer (Fischler, 1995). De este modo, la referida pérdida de la sociabilidad del hecho de comer hace que descienda el interés por seguir una serie de normas asociadas a dicho hecho, tales como no separar los codos del cuerpo, mantener el cuerpo derecho, no morder el pan, no beber o no hablar con la boca llena o mientras se mastica. Esas normas hacían que la comida fuera un acto tranquilo y pleno de significación socio-cultural, en contra de lo que ocurre actualmente, cuando aumentan las personas que comen mecánicamente y con prisas, simplemente 'porque hay que comer'. Uno de los efectos negativos de ello es la pérdida de autoridad de los padres que lleva a que muchos niños coman cuando, como y lo que quieren, lo que, a su vez, puede implicar la reproducción y transmisión futura de esos malos hábitos a las generaciones venideras (Bolaños, 2009: 962).

\section{A manera de conclusión}

En el aprendizaje de los hábitos de nutrición y de adquisición de alimentos tienen cada vez más influencia los medios de comunicación e información globales, lo cual está muy relacionado con la creciente preponderancia de éstos como orientadores de las vidas cotidianas. Junto con la agroindustria transnacional, tales medios desempeñan un decisivo papel en el establecimiento y la difusión planetaria de directrices estándar de producción, presentación y consumo de los alimentos.

Un objetivo prioritario es conseguir que los medios de comunicación no sean sólo instrumentos al servicio de los intereses de las grandes transnacionales alimentarias, sino que también colaboren en la educación para el consumo alimenticio haciendo campañas publicitarias tan imaginativas y seductoras como las que suelen implementar para atraer la atención de la población en tanto que consumidora (Ávila y Linares, 2006: 36-37). Por ejemplo, son necesarias estrategias informativas y de prevención que presenten, en la televisión, la publicidad o las revistas de moda, unas opciones de imágenes corporales distintas de aquellas que propugnan la extrema delgadez. Al mismo tiempo, tales estrategias deberían contribuir a dotar a los/as niños/as y a los/as jóvenes de habilidades y herramientas cognoscitivas que les capaciten para resistir y manejar proactivamente los mensajes mediáticos de perfección corporal. Al menos, los medios de comunicación públicos, en las democracias, tendrían que ayudar a reflexionar y a concienciar a los ciudadanos de la necesidad de buscar ayuda y consejo, proporcionándoles datos sobre lugares y especialistas a los que poder acudir para superar sus posibles problemas de salud derivados de trastornos alimenticios ocasionados por su subordinación a unas imágenes corporales irreales y prácticamente imposibles de conseguir (Behar, 2010: 330).

Afortunadamente, cada vez se extiende más la consciencia de que en publicidad 'no todo vale', por lo que hay que poner límites normativos a la manera de hacerla. Ello, que en gran parte se debe a la presión de la ciudadanía democrática, explica 
que una institución como el Parlamento Europeo, preocupado por el aumento de la obesidad en la infancia, trabaje para restringir la publicidad infantil de alimentos que son inapropiados por sus elevadas proporciones de grasas, azúcares o sal. A este respecto, conviene resaltar que la implicación de los poderes públicos y de la ciudadanía (por ejemplo, a través de las organizaciones de consumidores) puede resultar particularmente efectiva en la lucha contra cualquier forma de publicidad engañosa, contribuyendo a incrementar los controles y el grado de vigilancia, verificando que los etiquetados de los productos alimenticios ofrecidos en el mercado son correctos y especifican clara, detallada e inteligiblemente para la generalidad de los consumidores todos sus componentes y las proporciones de éstos.

En concreto, con respecto a los niños, dada su especial vulnerabilidad, los esfuerzos han de concentrarse en evitar toda forma de publicidad que explote su natural ingenuidad mostrándoles productos que les aportan una especie de 'superpoderes' o presentándoles hábitos de alimentación o modos de vida sedentarios y poco saludables causantes de obesidad (Pérez-Salgado, Rivera-Márquez y Ortiz-Hernández, 2010).

Un objetivo general prioritario debe ser el educar para un consumo responsable que capacite a las personas para elegir con racionalidad y reaccionar adecuadamente ante los excesos de la publicidad. Ello implica, entre otros aspectos, favorecer que los individuos desarrollen actitudes consumistas en tanto que sujetos sociales activos (Callejo, 1995). Las manifestaciones que de tales actitudes ya existen propician, en algunos casos, la aparición y extensión de una serie de preocupaciones cívico-políticas y sociales, las cuales se muestran, por ejemplo, en el hecho de preferir la adquisición de productos y marcas en cuya elaboración no se ha utilizado mano de obra infantil, ni han existido condiciones de contratación injustas o salarios indignos, y tampoco se han amenazado la seguridad, los empleos o el medio ambiente (Barber, 2001: 112).

Desde luego, dichas preocupaciones cívico-políticas no dejan de ser hoy actitudes minoritarias de ciertos grupos de interés y, por lo tanto, opciones más o menos testimoniales. Conseguir que el consumo de alimentos sea un ejercicio cívico, aunque sólo fuera para esa parte de la población mundial que está en condiciones de determinar soberanamente sus hábitos alimenticios, requeriría no sólo una mayor extensión de la educación nutricional de toda la ciudadanía (y de los niños en particular) para recuperar una alimentación saludable (Ayechu y Durá, 2010: 40-41), sino también un notable cambio de las estructuras socioeconómicas y políticas que permitiera que el consumo alimenticio fuera visto, además de como un hecho social, como una estrategia tendente a intentar la reconquista imaginativa de los espacios colectivos y el interés por lo público. Así, ese consumo se mostraría como un acto útil para pensar y actuar significativa y renovadoramente en la vida socio-política (García Canclini, 1995). Sin duda, ello debería ser una aspiración legítima en las democracias, entre cuyos requisitos institucionales están la libertad de expresión, el acceso a fuentes alternativas de información y la autonomía asociativa (Dahl, 2012: 100-101). 


\section{Referencias bibliográficas}

ALONSO, L. E. (2002). “Un nuevo consumidor?”. En: Ábaco. Revista de Cultura y Ciencias Sociales, n ${ }^{\mathrm{o}}$ 31, Gijón: CEES, Centro de Cultura y Ciencias Sociales. p. 11-18.

ÁVILA, C.; LINARES, F. (2006). "Léxico y discurso de la moda". En: Comunicar. Revista científica iberoamericana de comunicación y educación, $\mathrm{n}^{\circ} 27$, Huelva: Grupo Comunicar. p. 35-41.

AYECHU, A.; DURÁ, T. (2010). "Calidad de los hábitos alimentarios (adherencia a la dieta mediterránea) en los alumnos de educación secundaria obligatoria". En: Anales del Sistema Sanitario de Navarra, Vol. 33. n ${ }^{\circ}$ 1, Pamplona: Gobierno de Navarra. p. 35-42.

BARBER, B. (2001). A place for us. How to Make Society Civil and Democracy Strong. Nueva York: Farrar/Pantheon Books.

BEHAR, A. R. (2010). "La construcción cultural del cuerpo: El paradigma de los trastornos de la conducta alimentaria". En: Revista chilena de neuro-psiquiatría, Vol. $48, n^{\circ} 4$, Santiago (Chile): Sociedad de Neurología, Psiquiatría y Neurocirugía. p. 319-334.

BOLAÑOS RÍOS, P. (2009). "Evolución de los hábitos alimentarios. De la salud a la enfermedad por medio de la alimentación". En: Trastornos de la Conducta Alimentaria, $\mathrm{n}^{\circ}$ 9, Sevilla: Instituto de Ciencias de la Conducta Dr. Jáuregui. p. 956-972.

BOURDIEU, P. (1971). "Champ du pouvoir, Champ intéllectuel et habitus de clase". En: Scolies, $\mathrm{n}^{\circ}$ 1, París: Cahiers de recherche de l'Ecole normale supérieur. p. 7-26.

BOURDIEU, P. (1988). La distinción. Criterio y bases sociales del gusto. Madrid: Taurus.

CALLEJO, J. (1995). "Elementos para una teoría sociológica del consumo". En: Papers, Revista de Sociología, $\mathrm{n}^{\circ}$ 47, Barcelona: Universidad Autónoma de Barcelona. p. 75-96.

CONTRERAS-HERNÁNDEZ, J.; GRACIA-ARNAIZ, M. (2005). Alimentación y cultura. Perspectivas antropológicas. Barcelona: Ariel.

CORTI, A. M. (2005). "La estética de la imagen y la tiranía del éxito". En: Revista Electrónica de Psicología Política, año 2, no 8, San Luis (Argentina): Universidad Nacional de San Luis. Recuperado de http://www.psicopol.unsl.edu.ar/abril05_ nota4.htm [Consultado el 14-10-2013].

DAHL, R. A. (2012). La democracia. Barcelona: Ariel.

FISCHLER, C. (1995). El (h) omnívoro. El gusto, la cocina y el cuerpo. Barcelona: Anagrama.

GARCIA CANCLINI, N. (1995). Consumidores y ciudadanos. Conflictos multiculturales de la globalización. México: Grijalbo.

GOFFMAN, E. (1959). The presentation of self in everyday life. New York: Doubleday Anchor Books.

GONZÁLEZ-TURMO, I. (1995). Comida de rico, comida de pobre. Los hábitos alimenticios en el occidente andaluz (siglo XX). Sevilla: Universidad de Sevilla. 
GUERRERO, N.; CAMPOS, O.; LUENGO, J. (2005). Factores que intervienen en la modificación de los hábitos alimentarios no adecuados en la provincia de Palena. Programa de Diplomado en Salud Pública y Salud Familiar. Recuperado de http://www.medicina.uach.cl/postgrado/diplomados/saludpublica/trabajos.php [Consultado el 14-10-2013].

HARRIS, M. (1985). Good to eat. Riddles of food and culture. London: Allen and Unwin.

HIDALGO, M. I. (2003). "Nutrición en la edad preescolar, escolar y adolescente". En: Pediatría Integral, Vol. 7. $\mathrm{n}^{\circ}$ 5, Barcelona: Sociedad Española de Pediatría Extrahospitalaria y Atención Primaria (SEPEAP). p. 340-354.

INGLEHART, R. (1990). Culture shift in advanced industrial society. Princeton: Princeton University Press.

LÓPEZ NOMDEDEU, C. (coord.) (1999). Nutrición saludable y prevención de los trastornos alimentarios. Madrid: Ministerios de Sanidad y Consumo, Educación y Cultura e Interior.

MARÍN, V. (2006). "Medios de comunicación, educación y realidad". En: Comunicar. Revista científica iberoamericana de comunicación y educación, $\mathrm{n}^{\mathrm{o}} 26$, Huelva: Grupo Comunicar. p. 193-197.

MARTÍN-CRIADO, E.; MORENO-PESTAÑA, J. L. (2005). Conflictos sobre lo sano. Un estudio sociológico de la alimentación en las clases populares en Andalucía. Sevilla: Junta de Andalucía.

MARTÍNEZ BARREIRO, A. (2004). "La construcción social del cuerpo en las sociedades contemporáneas”. En: Papers: Revista de sociología, $\mathrm{n}^{\circ}$ 73, Barcelona: Universidad Autónoma de Barcelona. p. 127-152.

PÉREZ-SALGADO, D.; RIVERA-MÁRQUEZ, J. A.; ORTIZ-HERNÁNDEZ, L. (2010). "Publicidad de alimentos en la programación de la televisión mexicana: ¿los niños están más expuestos?”. En: Salud Pública de México, Vol. 52. n² 2, Cuernavaca (México): Instituto Nacional de Salud Pública. p. 119-126.

RAMOS, P.; RIVERA, F.; MORENO, C. (2010). "Diferencias de sexo en imagen corporal, control de peso e Índice de Masa Corporal de los adolescentes españoles”. En: Psicothema, Vol. 22, no 1, Oviedo (España): Colegio Oficial de Psicólogos del Principado de Asturias. p. 77-83.

RESTREPO, S. L.; MAYA-GALLEGO, M. (2005). "La familia y su papel en la formación de los hábitos alimentarios en el escolar. Un acercamiento a la cotidianidad". En: Boletín de Antropología, Vol. 19, n 36, Medellín, Antioquia (Colombia): Universidad de Antioquia. p. 127-48.

SCHÜTZ, A. (1974). El problema de la realidad social. Buenos Aires: Amorrortu.

SHILLING, Ch. (1993). The body and social theory. London: Sage.

VERGARA-LEYTON, E. Y RODRÍGUEZ-SALINEROS, M. (2010). "El impacto social y cultural de la publicidad entre los jóvenes chilenos". En: Comunicar. Revista científica iberoamericana de comunicación y educación, $\mathrm{n}^{\circ} 35$, Huelva: Grupo Comunicar. p. 113-119.

WARDE, A. (1997). Consumption, food and taste. London: Sage. 


\section{Los autores}

Francisco Entrena Durán es Doctor en Sociología y Catedrático de Sociología en la Universidad de Granada (España)

José Francisco Jiménez Díaz es Doctor en Sociología y Profesor de Ciencia Política en la Universidad Pablo de Olavide de Sevilla. 